\title{
Molecular characterization of hsp90 isoforms in colorectal cancer cells and its association with tumour progression
}

\author{
Z. MILICEVIC ${ }^{1}$, D. BOGOJEVIC ${ }^{2}$, M. MIHAILOVIC ${ }^{2}$, M. PETROVIC ${ }^{2}$ and Z. KRIVOKAPIC ${ }^{3}$ \\ ${ }^{1}$ Laboratory for Molecular Biology and Endocrinology, 'Vinca' Institute of Nuclear Sciences; \\ ${ }^{2}$ Department of Molecular Biology, Institute for Biological Research; ${ }^{3}$ Institute for \\ Digestive Diseases, Clinical Center of Serbia, Belgrade, Serbia
}

Received September 26, 2007; Accepted December 21, 2007

\begin{abstract}
A key role of hsp90 in the activity of various oncogenic proteins and pathways is currently of intense interest. To clarify the molecular basis of biological behaviour of colorectal cancers we analysed the expression characteristics of hsp90 in cytosolic, nuclear and plasma membranous fractions of cancer cells. As determined by Western blot assay all hsp90 isoforms studied, $\alpha(84 \mathrm{kDa}), \beta(86 \mathrm{kDa})$ and hsp90N (75 kDa), were up-regulated and differentially expressed in various stages of colorectal carcinoma. The inducible hsp $90 \alpha$ isoform is a component of invasive phenotype of cancer cells thus pointing to the importance of hsp90a for metastasis generation. The expression of hsp90ß is definitely higher in poorly-differentiated carcinomas than in well-differentiated cancers, suggesting an involvement of hsp90ß in the inhibition of cancer cell differentiation. Especially, the expression of cytosolic hsp90N isoform in malignant cells points to the possibility that induction or overexpression of hsp $90 \mathrm{~N}$ might be causally related to tumour formation. Hsp90N is the plasma-membraneassociated protein in poorly-differentiated colorectal cancers with metastasis. This suggests that the expression of hsp90N is elevated with progressive dedifferentiation often associated with advanced cancer stages. Hsp90 was exclusively localized in the invasive front in a majority of metastatic cancers as visualized by immunohistochemical study. Consistent with these facts, the frequent expression of hsp90 $\alpha$ and hsp90N on the surface of colorectal cancer cells may enable hsp90 to act as a mediator of metastasis generation. The above results indicate more complex roles for hsp90 in colorectal tumourigenesis. In this way, the hsp90 would be at the crossroads of both signalling and cell migration events.
\end{abstract}

Correspondence to: Dr Desanka Bogojevic, Institute for Biological Research, Blvd. Despot Stephan 142, Belgrade, Serbia

E-mail: dekana@ibiss.bg.ac.yu

Key words: hsp90, colorectal cancer, malignant progression

\section{Introduction}

Hsp90 is of interest because of its importance in maintaining the conformation, stability and function of key oncogenic proteins involved in signal transduction pathways leading to proliferation, cell cycle progression and apoptosis, as well as other features of the malignant phenotype such as invasion, angiogenesis and metastasis (1). Molecular chaperones help hundreds of signalling molecules to keep their activationcompetent state, and regulate various signalling processes ranging from signalling at the plasma membrane to transcription (2). Hsp90 participation in multimolecular complex formation may be required for induction of the transformed phenotype $(3,4)$. Such a requirement would not be surprising given that the assembly of multimolecular protein complexes has been shown to be a critical event in an increasing number of signal transduction pathways regulating cell growth and differentiation, survival and tumour-specific transformation $(5,6)$.

Hsp90 is present in multiprotein machine complexes that are predominant in cancer cells but not normal cells. The presence of these hsp90 complexes in tumour cells is consistent with a major role for hsp90 as the cancer chaperone-buffering and stabilizing metastable and potentially damaging mutant proteins during the evolution and progression of malignancy (7). This is consistent with the idea that hsp90 is absolutely required for malignant progression (8).

The hsp90 superfamily comprises the cytoplasmic chaperones hsp90 $\alpha$ and hsp90ß, together with the endoplasmic reticulum homologue Grp94 and the mitochondrial homologue TRAP1 (9). Grp94 and TRAP1 are involved in chaperoning proteins in their respective subcellular compartments, although the evidence for this is weak for TRAP1. Hsp90N, a variant of the cytoplasmic hsp90, has been previously identified and appears to be membrane associated (10). As described, hsp90N bound Raf-1 more tightly than hsp90 and it might recruit Raf- 1 to the membrane (10). Raf-1 is a serine/threonine kinase which participates in an evolutionarily conserved signalling cascade transducing signals from the plasma membrane to the nucleus (11). Raf-1 plays critical roles in cell growth and differentiation and induces the expression of early response genes (12). Raf-1 kinase associates with the hsp90 chaperone complex containing hsp90N, leading to 
Raf-1 stabilization and inhibiting its proteasome-dependent degradation (13).

The hsp90 chaperones are also of special relevance in human cancer among proteins inhibiting apoptosis fulfilling the criteria of anti-apoptotic members (14-17). There is also evidence that tumour cells with high MHC class I expression and susceptibility to CTL action may escape apoptosis by a mechanism which involves increased nuclear hsp90 (18). The question of how molecular chaperones function at key regulatory points in the control of apoptosis is currently of intense interest. As a result of this the overexpression of hsp90 is common in various human tumours, preferentially in malignant cancers, correlates with poor prognosis and resistance to therapy (19).

A further study (20) demonstrated that hsp90 play important roles in cell differentiation through the control of tyrosine kinase activities. Hsp90 has multiple cellular roles, many of which are poorly understood (21).

We focused on hsp90 $\alpha / \beta$, which are the best understood at the present time. Furthermore, hsp $90 \mathrm{~N}$ expression was analysed in colorectal cancer. The protein called hsp90N (75 kDa) is thought to have more specialized complex activities in the cell. In this instance, a strong correlation has been suggested between higher levels of hsp90N expression and neoplastic transformation, including interruption of gap junctional, intercellular communication and anchorageindependent proliferation (10).

\section{Materials and methods}

Subjects. Forty-eight surgically removed colorectal carcinoma and 12 normal colonic and rectal mucosal samples were examined. Thirty-two patients were male, and 16 were female. The mean age of the patients was 62 years (range: 33-80). The primary lesion was located in the rectum in 32 , the sigmoid colon in 8 , the descending colon in 4 , the transverse colon in 2 , the ascending colon in 1 , and the cecum in 1 of the patients. The histological classification of the tumours was established according to previous criteria (22). Thus, 20 were well differentiated adenocarcinoma, 10 were moderately differentiated adenocarcinomas, and 18 were poorly differentiated adenocarcinomas. All cancers were graded according to the AstlerColler's modified Dukes' stage as $\mathrm{A}, \mathrm{B}_{1}, \mathrm{~B}_{2}, \mathrm{C}_{1}$ and $\mathrm{C}_{2}$. The distribution of these tumours according to Astler-Coller system was stage $B_{1}, 6$ cases, stage $B_{2}, 26$ cases and stage $C_{2}, 16$ cases. Twelve normal colonic and rectal mucosal samples were selected from macroscopically normal areas; 6 samples were taken from the areas $>10 \mathrm{~cm}$ away from tumours, and 6 from normal mucosa of non-tumour patients. All of the samples were collected at the time of surgery, snap-frozen in liquid nitrogen, and stored at $-80^{\circ} \mathrm{C}$.

Tissue and cellular fractionation. The normal mucosa and colorectal cancer tissues were surgically dissected and frozen. The nuclear fraction of normal and tumour tissues were obtained by differential centrifugation (23), and the plasma membrane fraction was obtained by a modified method of Bauer and Hurtenbach (24). Briefly, the samples of normal and neoplastic tissue were minced by fine dissection and homogenized in $0.25 \mathrm{M}$ sucrose, $5 \mathrm{mM} \mathrm{MgCl}_{2}, 0.5 \%$ Triton
$\mathrm{X}-100,1 \mathrm{mM}$ phenylmethylsulfonyl fluoride (PMSF) and $50 \mathrm{mM}$ Tris- $\mathrm{HCl}$ ( $\mathrm{pH} \mathrm{7.4),} \mathrm{followed} \mathrm{by} \mathrm{centrifugation} \mathrm{of} \mathrm{the}$ homogenate at $800 \mathrm{x} \mathrm{g}$ for $10 \mathrm{~min}$. The supernatants were spun at $11000 \mathrm{x} \mathrm{g}$ at $4^{\circ} \mathrm{C}$ for $25 \mathrm{~min}$ and the resulting supernatant was again centrifugated at $20000 \mathrm{x}$ g at $4^{\circ} \mathrm{C}$ for $45 \mathrm{~min}$. The pellet, containing plasma membranes and associated proteins, was resuspended in $10 \mathrm{mM}$ Tris- $\mathrm{HCl}$ $(\mathrm{pH} 7.4)$ and stored at $-20^{\circ} \mathrm{C}$. The cytosolic fraction was obtained by further centrifugation of supernatant at $100000 \mathrm{x} \mathrm{g}$, at $4^{\circ} \mathrm{C}$ for $60 \mathrm{~min}$. The pellet obtained after first centrifugation was homogenized in ice-cold buffer $(2.2 \mathrm{M}$ sucrose, $5 \mathrm{mM}$ $\mathrm{MgCl}_{2}, 0.5 \%$ Triton X-100, $1 \mathrm{mM}$ PMSF and $50 \mathrm{mM}$ Tris- $\mathrm{HCl}$, $\mathrm{pH}$ 7.4) and further purified by centrifugation. After this step the pellets representing the soluble nuclear proteins were resuspended in $0.25 \mathrm{M}$ sucrose, $5 \mathrm{mM} \mathrm{MgCl}_{2}, 0.5 \%$ Triton $\mathrm{X}-100,1 \mathrm{mM}$ PMSF, and $50 \mathrm{mM}$ Tris- $\mathrm{HCl}, \mathrm{pH}$ 7.4. The protein concentration was determined by the Lowry method (25) and samples were aliquoted and stored at $-20^{\circ} \mathrm{C}$. The presence and purity of plasma membranes isolated from human colorectal cancer tissues and normal mucosa was examined by membranous NaK-ATPase activity, according to the methods described earlier $(26,27)$. ATPase activity was measured by colorimetric determination of inorganic phosphate (26), liberated from ATP. Incubation was carried out at $37^{\circ} \mathrm{C}$ for $10 \mathrm{~min}$ in a medium containing (in $\mathrm{mmol} /$ 1):50 Tris- $\mathrm{HCl}, \mathrm{pH} 7.6,1$ EGTA, $5 \mathrm{MgCl}_{2}, 1$ ATP and $20 \mu \mathrm{g}$ of membrane preparation in a final volume of $200 \mu 1$. Only the samples which displayed NaK-ATPase activity were considered as pure and taken for further analyses.

Western blot analysis. Proteins isolated from normal mucosa and colorectal cancer cells were suspended in sample loading buffer $(0.1 \mathrm{M}$ Tris, $\mathrm{pH}$ 6.8, 20\% glycerol, 4\% SDS, $0.04 \%$ bromophenolblue, $10 \%$ B-mercaptoethanol), and separated electrophoretically on $12 \%$ acrylamide gels, according to the procedure of Laemmli (28). Approximately $50 \mu \mathrm{g}$ of nuclear, $20 \mu \mathrm{g}$ of cytosolic and $80 \mu \mathrm{g}$ of plasma membrane proteins per lane was loaded and run on $12 \%$ SDS-PAGE. Separated proteins were transferred onto nitrocellulose membrane (Hybond, Amersham) according to the procedure of Towbin et al (29). Transfer of proteins from the acrylamide gel to nitrocellulose was performed in transfer buffer $(25 \mathrm{mM}$ Tris, $192 \mathrm{mM}$ glycine, $0.1 \%$ SDS, $20 \%$ methanol, $\mathrm{pH} 7.5$ ) at $30 \mathrm{~V}$, $40 \mathrm{~mA}$ overnight at $4^{\circ} \mathrm{C}$. Nitrocellulose filters were blocked overnight with blocking buffer $(1 \%$ BSA in $50 \mathrm{mM}$ Tris, $0.9 \% \mathrm{NaCl}, 0.05 \%$ Tween-20, $\mathrm{pH} 7.5)$. The filters were then incubated for $1 \mathrm{~h} 45 \mathrm{~min}$ in buffer $(50 \mathrm{mM}$ Tris, $0.9 \% \mathrm{NaCl}$, $0.05 \%$ Tween-20, $\mathrm{pH} 7.5$ ) containing the mouse monoclonal antibodies at the indicated dilution (AC88 1:1000; H9010 1:500). After $1 \mathrm{~h}$ of incubation with the AP-conjugated goat anti-mouse IgG $(\mathrm{H}+\mathrm{L})$ antibodies (ICN Pharmaceuticals) (diluted 1:1000) the proteins bands were visualized in a alkaline phosphatase substrate 5-bromo-4-chloro-3-indolylphosphate and nitroblue tetrazolium (NBT/BCIP) (Gibco). Scanning densitometry was used to determine peak areas to assess the relative amount of protein in immunoreactive bands. The bands representing the hsp90 immunoreactivity were scanned by a computer-based laser densitometer (Pharmacia Ultra Scan XL). The duplicate gel was directly stained with Coomassie Brilliant Blue R250 to confirm equal loading 

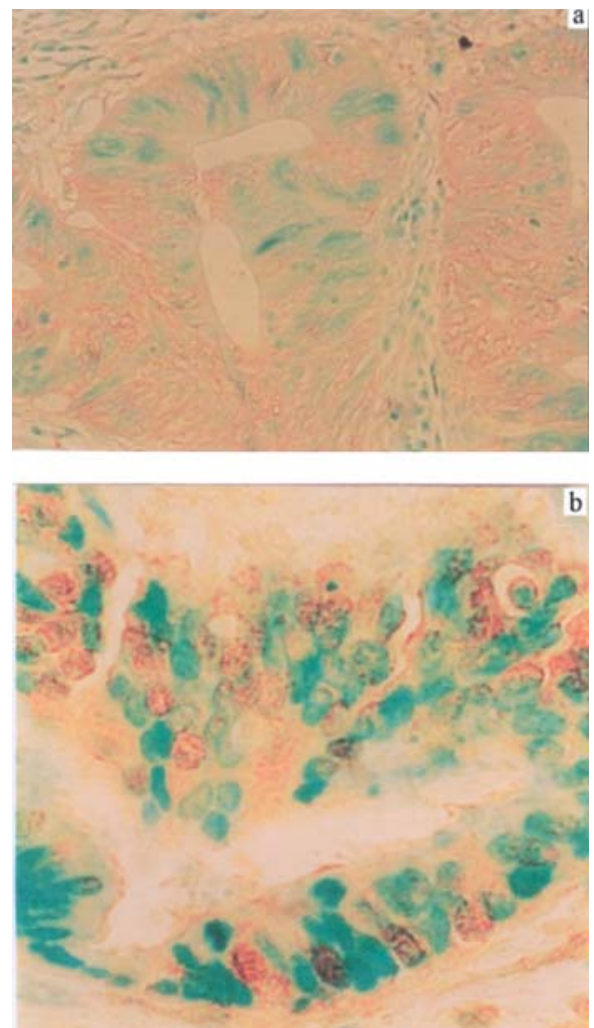

Figure 1. Immunohistochemical staining of hsp90 in (a) well-differentiated low-grade tumour stage $\mathrm{G}_{1} \mathrm{~B}_{1}$ and (b) high-grade invasive tumour stage $\mathrm{G}_{3} \mathrm{C}_{2}$. (a) Hsp90 is expressed on the plasma membrane of tumour cells. (b) The signal is more intense at the cell-surface of single malignant cells. Diffuse cytoplasmic and nuclear hsp90 staining is evident in advanced malignant carcinoma. Avidin-biotin-peroxidase complex (ABC) method, counterstained with methyl green.

among the lines. Reproducibility was assessed by repeating the protein extraction and the SDS-PAGE three times.

Immunohistochemical studies. Immunohistochemical staining was performed on $3 \mu \mathrm{m}$ tissue sections by an avidin-biotinperoxidase complex $(\mathrm{ABC})$ technique using both frozen and formalin-fixed paraffin-embedded tissues. For formalin-fixed paraffin-embedded sections, we applied the microwave oven heating technique, shown to be effective for the retrieval of masked epitopes of many antigens. The primary antibodies used were mouse monoclonal antibody AC88, which has a broad spectrum of species cross-reactivity against hsp90, including human hsp90 (30), kindly provided by Dr David O. Toft (Mayo Clinic, Rochester, MN). Briefly, after dewaxing, endogenous peroxidase activity was blocked by incubating the sections with methanol containing 3\% hydrogen peroxide for $20 \mathrm{~min}$. After preincubation with normal goat serum for $20 \mathrm{~min}$ a three-step immunoperoxide procedure was applied: the first step incubated the primary antibodies AC88 at the appropriate working dilution $\left(1: 500\right.$, overnight at $\left.4^{\circ} \mathrm{C}\right)$, the second biotinylated goat anti-mouse immunoglobulin (Dako, Denmark, E-433) diluted 1:300 $45 \mathrm{~min}$ at room temperature, and the third peroxidase-linked avidin-biotin complex (Dako), 1:250 diluted, $30 \mathrm{~min}$ at room temperature. The peroxidase activity was developed by $0.06 \% \mathrm{H}_{2} \mathrm{O}_{2}$ and $0.03 \%$ 3,3'-diaminobenzidine tetrahydrochloride for $5 \mathrm{~min}$. After immunostaining,
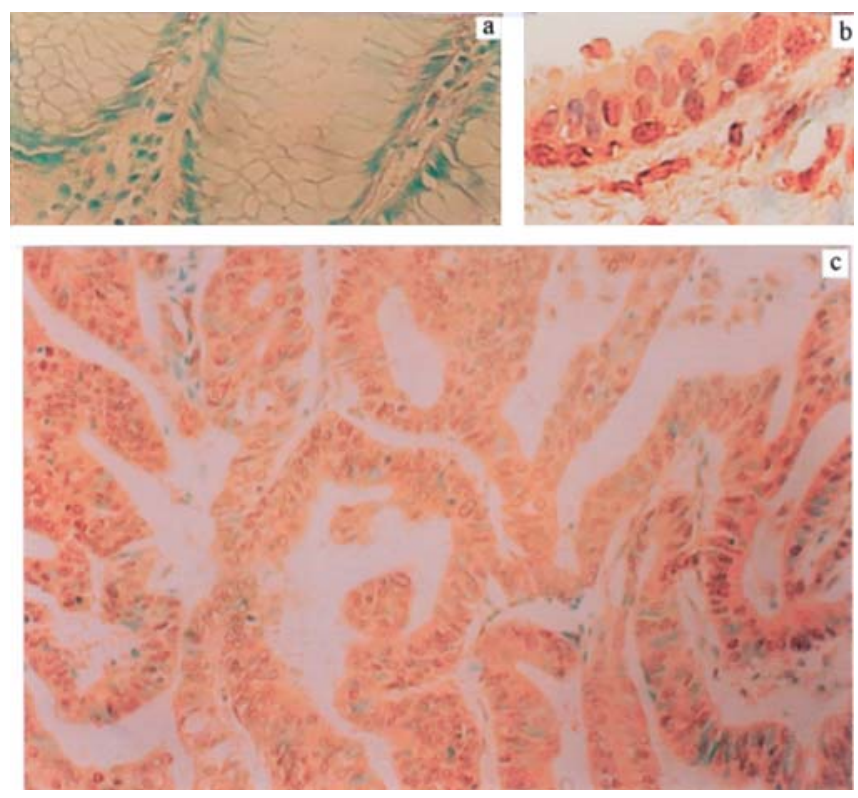

Figure 2. Immunohistochemical staining of hsp90 in normal and tumour tissues. (a) A weakly hsp90 immunoreactivity is seen in the cells of normal rectal mucosae. (b) Human breast cancer exhibit strong hsp90-positive staining. (c) Invasive well-differentiated rectal cancer stage $G_{1} C_{1}$. Note the strong expression of hsp90 in the cytoplasm and on the surface of tumour cells. The number of positive cells is increased and staining intensity is greater. Avidin-biotin-peroxidase complex (ABC) method, counterstained with methyl green.

the sections were lightly counterstained with methylgreen $(0.5 \% ; 2 \mathrm{~min})$ to visualize nuclei. We studied the tissue samples by assessing the site of staining, the proportion of cell staining (counting at least 1000 cells/sample) and the intensity of staining: weak $(+)$, moderate $(++)$ or strong $(+++)$. In the negative control slides (absence of immunostaining) the primary antibodies were replaced with normal mouse serum. Positive controls included human breast cancer (Bio Genex heat shock protein control FG289M).

Statistical analysis. The significance of differences between different experimental values was assessed by means of Anova and Student's t-test. Results were considered to be significant at $\mathrm{p}$-value $<0.05$. In all cases the same degree of significance was obtained with both tests. All statistical manipulations were performed using the SPSS for Windows software system (SPSS Inc., Chicago, IL).

\section{Results}

To explore the potential role of hsp90 family members in the malignant metastatic progression of human colorectal cancer, we initiated the present study by analyzing the expression profiles of hsp90 family members in various stages of colorectal carcinoma (during the evolution and progression of malignancy from pre-malignant lesions to invasive carcinomas). Preliminary study showed that not only frozen, but also formalin-fixed paraffin-embedded sections were positively stained with the mAbs H9010 and AC88; therefore, the latter were used for the immunohistologic staining study. Representative staining patterns are illustrated in Figs. 1-3. As 

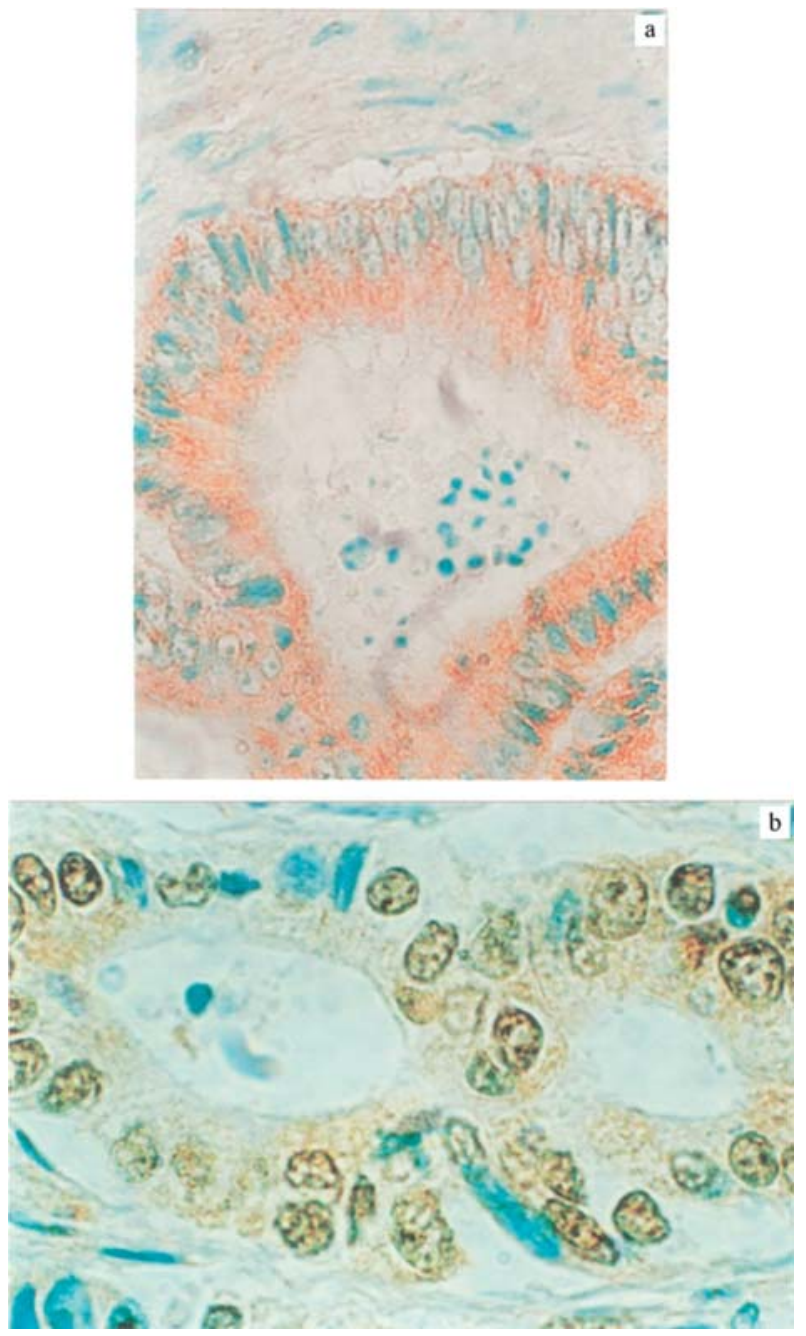

Figure 3. Hsp90 immunostaining in malignant cells from a high-grade rectal cancer $G_{2} C_{2}$ (a) and $G_{1} C_{1}$ (b). (a) In this case cytoplasmic and to a lesser extent nuclear staining was observed. Note the immunoreactivity of cell membrane in the invasive front of tumour. (b) Hsp90 immunoreactivity in both cytoplasmic and nuclear regions of nearly all cancer cells. Hsp90 is associated with the plasma membrane. Avidin-biotin-peroxidase complex (ABC) method, counterstained with methyl green.

shown, immunohistochemically detected hsp90 was mainly located in the cytoplasm and nucleus of the cancer cells. Hsp90 was found in $100 \%$ of the specimens. The degree and intensity of immunoreactivity were uneven, differing from cell to cell in the same tumour and among various carcinomas. Cases with high percentages of immunopositive neoplastic cells demonstrated intense staining (Fig. 2c). The number of hsp90 positive tumour cells tended to be higher in tumours with detectable lymph node metastases (Figs. 1b, 2c and 3a and b). Dispersed fine granules of moderate density, diffusely distributed throughout the cytoplasm, represented a common pattern of immunoreactivity in low-grade tumours (Fig. 1a). Strong immunopositivity was commonly noted in high-grade invasive tumours (Figs. $1 \mathrm{~b}$ and $2 \mathrm{c}$ ). The expression of the hsp90 increases as colorectal tumours progress from normal tissue through various degrees of displastic adenoma to carcinoma (data not shown). In the central differentiated area of the tumour, hsp90 overexpression was detected in both

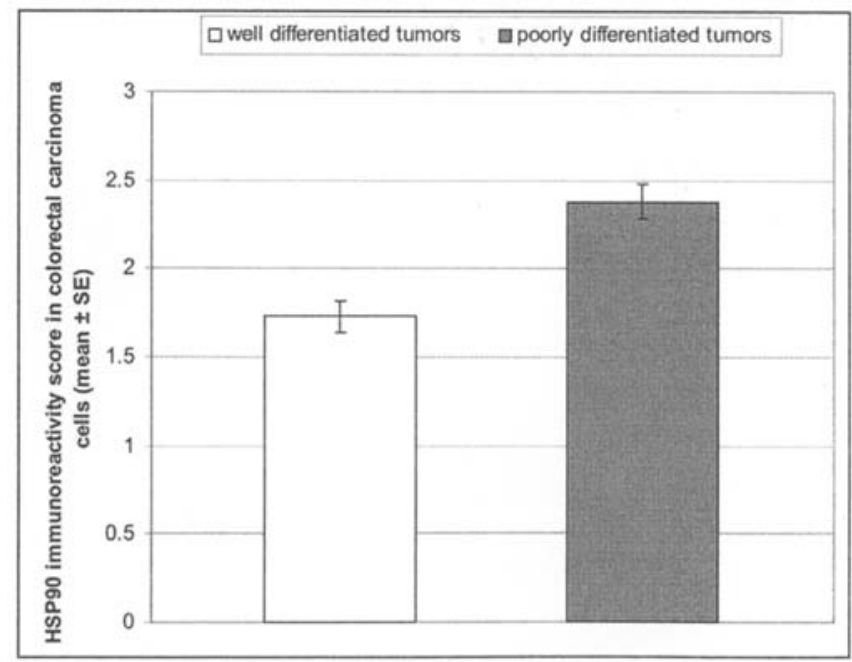

Figure 4. Expression of cytoplasmic hsp90 according to degree of tumour differentiation. The statistically significant difference in the score of cytoplasmic hsp90-immunoreactivity was found between the well-differentiated and poorly-differentiated colorectal adenocarcinoma.

the membrane and cytoplasm, and often in the nuclei of cells (Fig. 2c). The invasive front of tumours displayed strong hsp90 expression at the interphase between tumour and normal tissue (Fig. 3a). Higher magnification of the invasive tumour front displayed strong hsp90 expression in invading tumour cells and also in disseminated single tumour cells expressing nuclear hsp90 (Fig. 3b). Invasive colorectal cancers appeared to be more immunoreactive than superficial tumours. These results indicate that hsp90 might be an important component of invasive phenotype of tumour cells. The statistically significant difference in the score of cytoplasmic hsp90immunoreactivity was found between the well-differentiated and poorly-differentiated colorectal adenocarcinoma (Fig. 4). Furthermore, Dukes' C stage groups of colorectal neoplasms showed distinct higher positive rates than Dukes' A and B stage groups of tumours. A positive cell surface staining was detectable for hsp90. Membrane expression of hsp90 was also elevated in intracellular hsp90 overexpressing carcinoma cells. In the histologically normal rectal epithelium, we observed variable degrees of cytoplasmic staining for hsp90 along the whole length of the crypts (Fig. 2a).

Immunoblot analysis of the cytoplasmic protein fraction confirmed that the hsp90 is markedly increased in colorectal cancers [3-6 fold higher by scanning densitometry (Fig. 5B)]. The anti-hsp90 antibody H9010 detected three closely spaced bands with the molecular mass of 86,84 and $82 \mathrm{kDa}$ and another at $75 \mathrm{kDa}$ (Fig. 6). The latter form has been found only in colorectal cancer cells. These data suggested that hsp90N isoform $(75 \mathrm{kDa})$ might be associated with a tumour formation.

Two cytosolic isoforms of hsp90, hsp90a (84 kDa) and hsp90ß $(86 \mathrm{kDa})$ are differentially expressed in various stages of colorectal carcinoma (Figs. 5 and 6). It is likely that the inducible hsp90 $\alpha$ isoform is a component of invasive phenotype of tumour cells. However, the expression of hsp90ß isoform is definitely higher in poorly-differentiated carcinomas 


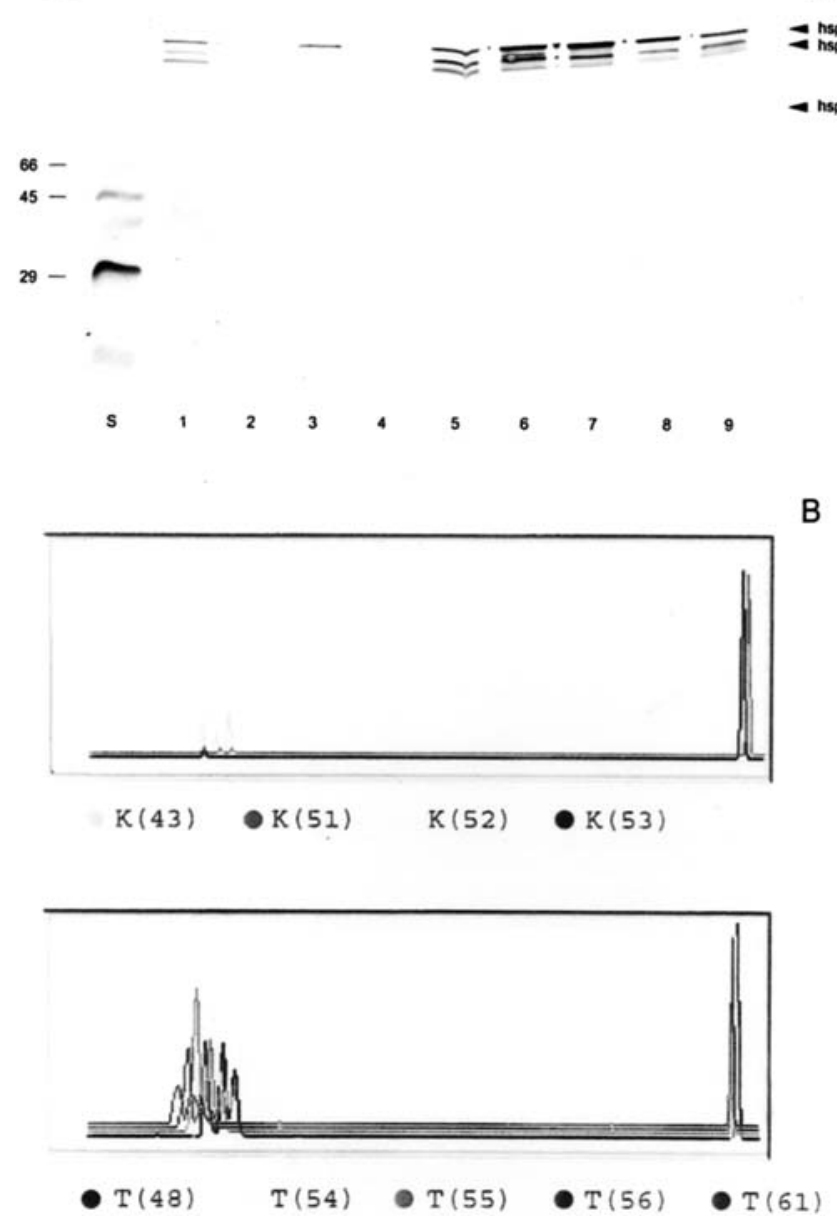

A A moses

hsp900

Figure 5. (A) Western blot analysis of hsp90 expression in cytoplasmic fraction of colorectal cancer cells. Differential stage-dependent expression of cytosolic hsp90 isoforms. Hsp90 migrated as three closely spaced bands $(86,84$ and $82 \mathrm{kDa})$. Two cytosolic isoforms of hsp90, $\alpha$ and $\beta$, are differentially expressed in various stages of colorectal carcinoma. A higher level of hsp90 $\alpha$ isoform $(84 \mathrm{kDa})$ and hsp90ß ( $86 \mathrm{kDa})$ seems to be closely correlated with the colorectal cancer progression. Hsp90ß isoform expression was significantly higher in poorly-differentiated carcinomas than in welldifferentiated colorectal cancers. Cytosolic extracts were prepared as described in Materials and methods. Proteins (20 $\mu \mathrm{g}$ per lane) were electrophoresed on a $12 \%$ polyacrylamide gel and immunoblotted with the antihsp90 antibodies $\mathrm{H} 9010$ at the dilutin of 1:500 and AP-conjugated goat anti-mouse $\operatorname{IgG}$ at the dilutin 1:1000. Visualization of signals was performed by NBT/BCIP solution. The data shown are from one representative set of three independent experiments. Molecular mass markers are presented on the left (S). The position of the hsp90 is indicated by the arrowheads. The arrowhead indicates an hsp90N (75 kDa) isoform; lanes 1-4, normal mucosa; lanes 5-9, colorectal cancer $\mathrm{G}_{1} \mathrm{~B}_{2}, \mathrm{G}_{1} \mathrm{C}_{2}, \mathrm{G}_{3} \mathrm{C}_{2}, \mathrm{G}_{1} \mathrm{~B}_{1}, \mathrm{G}_{1} \mathrm{C}_{2}$. (B) Densitometric quantification of the expression of hsp90. The intensity of the bands was determined densitometrically. Significant increase of the hsp90 in cytosolic fractions of colorectal cancer is evident. $\mathrm{K}$, normal tissue (pattern nos. 43, 51-53); T, tumour tissue (pattern nos. 48, 54-56, 61).

than in well-differentiated colorectal cancers, suggesting an involvement of hsp90ß in the inhibition of cancer cell differentiation. The expression of hsp90 in poorly-differentiated colorectal cancer with metastasis was definitely higher than that in well-differentiated colorectal cancer without metastasis (Fig. 5). Surprisingly, high expression of hsp90 are typically found in 'normal' tissue surrounding tumours. The 'normal' tissue (Fig. 6, lanes 2 and 4) shows a higher level of hsp90//B,

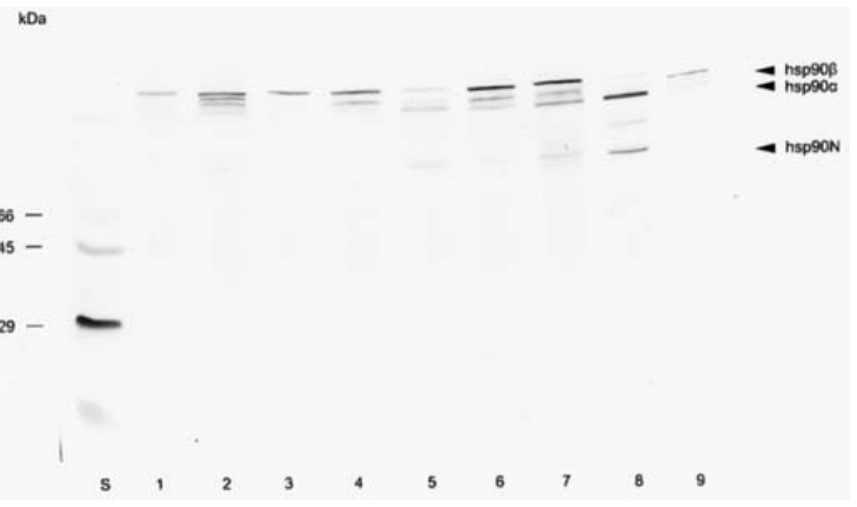

Figure 6. Hsp90 levels assayed by Western blotting in the cytoplasmic fractions of colorectal cancer cells. Hsp90 overexpression in pre-neoplastic and neoplastic lesions. Note the hsp90N expression in the cytoplasm of cancer cells. The signal is more intense in the invasive colorectal cancer stage $\mathrm{G}_{2} \mathrm{C}_{2}$ (lane 8). The inducible hsp90 $\alpha$ isoform is a component of invasive phenotype of tumor cells. Proteins ( $20 \mu \mathrm{g}$ per lane) were electrophoresed on a $12 \%$ polyacrylamide gel and immunoblotted with the H9010 antibody at the dilution of 1:500 and AP-cojugated goat anti-mouse IgG at the dilution 1:1000. Immunoreactive proteins were visualized with an NBT/BCIP (Gibco). Numbers refer to the relative molecular mass in kilodaltons of the standard proteins (S). Lanes 1 and 3, normal mucosa; 2 and 4, preneoplastic lesions; lanes 5-9, colorectal cancer, $\mathrm{G}_{2} \mathrm{C}_{2}, \mathrm{G}_{1} \mathrm{C}_{2}, \mathrm{G}_{2} \mathrm{~B}_{2}$, $\mathrm{G}_{2} \mathrm{C}_{2}, \mathrm{G}_{3} \mathrm{C}_{2}$ (interstitial type).

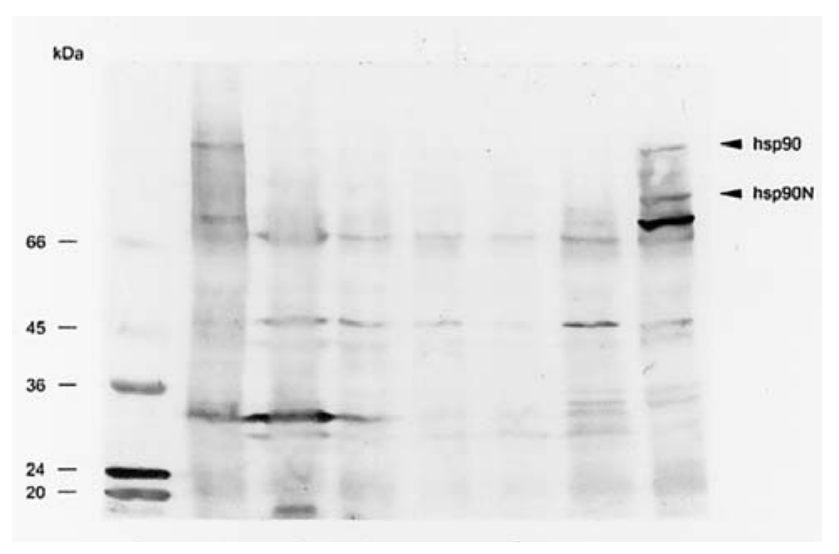

Figure 7. Western blot analysis of hsp90 expressed on the plasma membrane of colorectal cancer cells. Indicated by intense band, high amounts of hsp90 were present in plasma membrane of poorly-differentiated adenocarcinoma stage $\mathrm{G}_{3} \mathrm{C}_{2}$. We did not distinguish between hsp90 $\alpha$ and $\beta$ in the present analyses of different types of lesion. Membrane expression of hsp90N $(75 \mathrm{kDa})$ is significantely higher in poorly-differentiated cancer. Proteins (80 $\mu \mathrm{g}$ per lane) were subjected to SDS-PAGE and probed with anti-hsp90 antibodies H9010 and AP-cojugated goat anti-mouse IgG, all at a dilutin of 1:500. Immune complexes were detected using the substrate NBT/BCIP (Gibco). Left margin, molecular mass standard (s). The position of the hsp 90 is indicated by the arrowheads. Lanes 1 and 2, normal mucosa; lanes 3-7, colorectal cancer $\mathrm{G}_{1} \mathrm{~B}_{1}, \mathrm{G}_{2} \mathrm{~B}_{2}, \mathrm{G}_{1} \mathrm{C}_{2}, \mathrm{G}_{1} \mathrm{C}_{2}, \mathrm{G}_{3} \mathrm{C}_{2}$ (Dukes' stage and degree of differentiation).

as evidenced by the presence of abnormal clones of cells in morphologically normal mucosa. The analysis indicated a hsp90 overexpression in pre-neoplastic and neoplastic lesions. Additionally, we identified the hsp90 at the plasma membranes of colorectal cancer cells. Hsp90 was originally thought to be ubiquitously expressed as a cytoplasmic protein whose function was to capture folding intermediates to prevent protein 
misfolding and aggregation and to facilitate proper refolding.

We found by analysis that hsp90 is associated with the plasma membrane of colorectal carcinoma cells. The most prominent band of hsp90 was detected in the case of poorlydifferentiated colorectal adenocarcinoma $\left(\mathrm{G}_{3} \mathrm{C}_{2}\right)$, in general, more aggressive and with worse prognosis than moderately and well differentiated tumours (Fig. 7, lane 7). The same protein is present in trace amounts in corresponding nonneoplastic colonic mucosa excluding the muscle layer, from the same patient (Fig. 7, lane 2). Membrane expression of hsp90 was also elevated in normal mucosa tissue collected by dissection from macroscopically normal areas from patients to whom colorectal cancer tissues were surgically removed (Fig. 7, lane 1). This might in part explain the appearance of hsp90 at the surface of normal mucosa cells.

However, we did not distinquish between hsp90 $\alpha$ and $B$ in the present analyses of plasma membranes (Fig. 7). Moreover, it has been shown that the anti-hsp90 monoclonal antibody H9010 cross-reacted with additional hsp90-like proteins (Fig. 7).

\section{Discusion}

Increasing evidence indicates that colorectal cancer is a genetically heterogeneous and complicated disease (31-33). In the invasion and metastasis of colorectal cancer many genes have been identified as being involved in proteolysis, adhesion, angiogenesis and cell growth (34). The hsp90 molecular chaperone catalyses the final activation step of many of the most important regulatory proteins of eukaryotic cells (2). They participate in almost every remodeling event involving larger protein complexes, including signalling, transcription, cell division, migration, and differentiation (2).

In transformed cells, numerous mutated and overexpressed proteins rely on the hsp90 protein folding machinery for tumour progression. The heat-shock proteins hsp70 and hsp90 induced by cell stress are expressed at high levels in a wide range of tumours and are closely associated with a poor prognosis and resistance to therapy. The increased transcription of hsps in tumour cells is due to loss of p53 function and to higher expression of the proto-oncogenes HER2, c-Myc, k-ras and other genes is crucial to tumourigenesis (35). The hsp family members play overlapping essential roles in tumour growth both by promoting autonomous cell proliferation and by inhibiting death pathways (36). By chaperoning key proteins such as Raf-1, Akt, survivin and hTERT, hsp90 regulates signalling pathways necessary for the growth, survival and limitless replicative potential of most tumours. Important elements of the apoptotic pathways are also regulated by hsp90 (36). The variety of functions attributed to hsp90 proteins suggest the potential role of hsp90 in colorectal carcinogenesis.

The important finding of this study is that elevated expression of hsp $90 \alpha / \beta$ as well as the hsp90N isoform commonly observed in colorectal cancers analyzed are often associated with more invasive and metastatic phenotypes. It should be pointed out that there was a definite correlation between expression of hsp90 and development and metastasis of colorectal cancers. It was shown that the expression of hsp90 in poorly-differentiated colorectal cancer with metastasis was definitely higher than that in welldifferentiated colorectal cancer without metastasis, indicating that up-expression of hsp90 is likely to have some relationship with progression, invasion and metastasis of colorectal cancer. Additionally, we support the idea that the high hsp90 expression may lead to the identification of the earliest pathological features initiating colorectal tumourigenesis. Furthermore, overexpression of the hsp90 protein is also a feature of pre-invasive colorectal carcinomas. In these cases greater staining for hsp90 protein has been detected in the invasive margins of the tumours. This evidence suggests that hsp90 family are likely to be one of the critical players in colorectal cancer both in the initiation stage and during invasion and metastasis.

Essentially, there are indications that changes in proliferation-related genes such as hsp90 may occur in a progressive fashion and that this may be reflected in the association of hsp90 overexpression with tumour grade and the degree of differentiation. Thus, we have attempted, and hopefully achieved herein, a conceptual as well as a factual synthesis of the biological processes of invasion, proliferation, and metastasis, by linking the biological processes of cancer invasion and secondary spread with cell proliferation and its deregulation. It seems reasonable therefore to regard that hsp90s contribute significantly to the invasive propensity of cancer cell and are powerful modulators of metastatic behaviour.

Although a great deal of information is currently available regarding the structure of the hsp90 complex and its regulation, the involvement of this protein in biological processes such as proliferation and differentiation requires further investigation. Nevertheless, it should be remembered, that the hsp90 functions in certain aspects of cellular differentiation. Yamada et al (20) found that hsp90 showed remarkably high expression in undifferentiated human embryonal carcinoma cells. As a result, c-src tyrosine kinase was associated with hsp90 in undifferentiated cells. These results suggest that hsp90 may play important roles on cell differentiation through the control of tyrosine kinase activities (20). In addition, differentiation of embryonal carcinoma cells is paralleled by the induction of hsp90ß (37) and a non-identified isoform of hsp90 (38). Hsp90 binds to a wide variety of cellular proteins and is thought to play a role in a number of physiological processes including chromatin condensation (39), protein synthesis (40), protein folding (41) and protein trafficking (42). More importantly, it has been shown that hsp90 functions in the regulation of the cell cycle $(43,44)$, growth and differentiation processes $(45,46)$. In this respect, hsp90 may be involved in one or more of these phenomena during development of the colorectal cancers.

Hsps and the heat-shock response have been shown in a number of settings to protect against apoptosis $(14,16,17,22)$. Noteably, hsp90 is at a crossroad for multiple signalling pathways $(6,7)$. It is becoming clear that hsp90 chaperoning is not only essential to a variety of signal transduction pathways, but is also critical for proper folding, stabilization and trafficking of an expanding list of proteins. Three components of the MAP kinase signalling system (src, raf and mek) exist in complexes with hsp90 and a $50 \mathrm{kDa}$ 
protein that is the mammalian homolog of the yeast cell cycle control protein cdc37 (47). This suggests that binding to hsp90 is in some way related to the transforming activity of src. These heterocomplexes are formed by a multiprotein chaperone machinery consisting of at least four ubiquitous proteins, hsp90, hsp70, p60 and p23 (47). Hsp90 affects both the stability and localization of the p53 mutants (48). Using a temparature-sensitive mutant of p53, Sepehrnia et al (49) found that at the nonpermissive temperature, p53 mutant was localized in the cytoplasm and in a heterocomplex with hsp90, whereas at the permissive temperature, the p53 was nuclear and not immunoadsorbed with hsp90. Thus, as for the GR, hsp90 affects both the stability and localization of the p53 mutants.

Hyperactivation of growth promoting target genes of B-catenin-TCF signalling including c-myc may promote the onset of oncogenesis. The c-myc proto-oncogene encodes a ubiquitous transcription factor involved in the control of cell growth and differentiation and is implicated in inducing colorectal tumourigenesis (32). Understanding the function of c-myc and its role in cancer depends upon the identification of c-myc target genes. The findings of Teng et al (50) that c-myc directly activates hsp90 $\alpha$ transcription suggest that by induction of hsp $90 \alpha$ c-myc may control the activity of multiple signal pathways involved in cellular transformation.

Although not as extensively analyzed, hsp90 $\alpha$ expression in particular is crucial in cancer $(51,52)$. It is noteworthy that hsp90 has a significant role in triggering complex biological processes such as cell proliferation, differentiation or transformation (53). In fact, both hsp90 and grp94 are frequently up-regulated in tumour cells experiencing various types of stress, such as acidic $\mathrm{pH}$, a scarcity of nutrients, and fluctuations of oxygen supply (54). Thus, constitutively elevated levels of hsp90 were found in ras-transformed cells (51), other malignant cell lines (55-57), acute leukemias $(52,58)$, melanomas $(59)$, gastrointestinal cancers $(60)$, ovarian cancers (61) and in pancreatic and endometrial carcinomas $(62,63)$. Grp94 was found to be up-regulated in colon adenocarcinoma (64) and in large, radiation-induced mouse fibrosarcomas (65). Both hsp90 and grp94 are overexpressed in human breast cancer (66-68) where overexpression of hsp90 $\alpha$ is usually associated with poor prognosis (69). Complementing these changes, the downregulation of hsp90ß has been observed in the invasive and tumourigenic BC-61 subline of 8701-BC breast carcinoma cells (70). A higher level of heat-shock proteins, particularly hsp90 $\alpha$ seems to be closely correlated with the overall proliferative potential of malignant cells. This is in perfect agreement with the results described above and these data strongly support the idea that hsp90 is involved in the development of a colorectal carcinomas.

Elevated levels of heat-shock proteins may participate in the reorganization of chromatin structure, help in the maintenance of estrogen-dependent growth $(71,72)$ and confer a significant advantage on tumour cells to survive in a hostile environment. Increased amounts of hsp90 may also lead to an increased drug resistance of certain tumours (73).

Following the idea that the changes in gene structure and/or in the level of gene expression as a consequence of genome rearrangements are frequent in tumour cells, one might speculate that among possible rearrangements, gene amplifications are often involved in colorectal tumourigenesis. Difficulties, especially in the context of multiple genomic rearrangements, are encountered in ascertaining whether the overexpression of a given gene is the direct consequence of a change in its copy number or of the overexpression of non-amplified alleles. Jolly et al (74) have shown in human A431 carcinoma cells, that increased expression of the hsp90ß gene is due at least in part, to gene amplification. The amplification of the hsp90ß gene may involve an adjacent oncogene, such as the pseudo-gene v-Kiras1, which maps to the Gp12-6p11 region (75). Therefore, abnormalities of this gene may appear early in tumour development or in late stages of progression of colorectal cancers.

Hsp90 action on the cell surface might be a wide-ranging phenomenon. Hsp90 has been implicated in peptide antigen presentation to macrophages and dendritic cells (76). This suggests the possibility that hsp90 chaperones a broad array of proteins and peptides in the extracellular space that act in a variety of cellular processes.

In addition to promoting signalling events, hsp90 also functions in the processes of cell migration. Invasion and metastasis are exceedingly complex processes, and their genetic and biochemical determinants remain incompletely understood (77). An understanding of the means by which tumour cells achieve metastatic dissemination is obviously of crucial importance for successful treatment of the disease and for evolving possible strategies for the prevention of secondary spread. Although in the clinical context the events associated with the generation of metastatic and drug resistant phenotypes within the tumour contribute significantly to failure of treatment, these events are still poorly understood at the biochemical and molecular biological level. Current postgenomic strategies are being applied to identify genes and their encoded proteins that function in tumour invasion. Eustace et al (78) showed that the hsp90 $\alpha$ isoform, but not hsp $90 ß$, is expressed extracellularly on fibrosarcoma and breast cancer cells: hsp90 $\alpha$ interacts with the matrix metalloproteinase 2 (MMP2) outside the cell and promotes MMP2 activation, which is critical for tumour invasiveness. This finding extends the multiplicity of roles assigned to the hsp90 family to a new function outside the cell. The cytosolic molecular chaperone hsp90 is now shown to promote maturation of the extracellular MMP2 required for the invasive nature of cancer cells (79). Therefore, the overexpression of hsp90 in tumour cells stimulates the metastatic process.

Malignant tumours are known to be heterogeneous with respect to the expression of biochemical markers, degree of differentiation, and immunogenicity. It is now generally accepted that they are not composed of cells of equal metastatic potential but contain a variety of subpopulations with widely differing invasive and metastatic capabilities, proposing that tumour development involved traverse through different stages where the neoplasm could be seen to acquire cellular and functional features that could be used to define its progression. Thus, there will exist subpopulations with diverse biological properties, including metastatic potential, depending on the degree of progression undergone by the tumour. Although our 
original observations constitute an initial descriptive study these studies provide a basis for further studies in this area.

The evolution of cellular diversity within tumours is a significant feature of the development and progression of neoplasms. Not only is this phenomenon scientifically most challenging and conceptually most intractable, but it also has deep connotations for the treatment of cancer. Therefore, the generation of drug-resistant variants and variants with different degrees and patterns of metastatic ability is an area of tumour biology that is currently receiving considerable attention. It seems that the appearance of drug-resistant variants and metastatic phenotypes may be linked closely enough to make attempts at understanding the mechanisms involved a highly worthwhile objective in cancer research. It may be fortunate that they may be linked since our ability to deal with drugresistant variants and metastatic phenotypes is arquably the single most important factor that will determine success in the efforts to contain and cure the disease. These variants are genetically stable phenotypes, although phenotypic drift can and does occur in metastatic phenotypes under certain conditions. Interactions which might take place between different subpopulations within a tumour have often been credited with the maintenance of the stability of the metastatic phenotype. Therefore, studying the role of hsp90 for understanding the basis of the evolution of the metastatic phenotype is a logical step forward.

Although our basic understanding of the role of hsp90 in cancer biology has come a long way in a short time, the next several years hold the hope of similar progress in translating these findings to the improved treatment of cancer.

The precise mechanisms by which hsp90 participate in carcinogenesis are still not fully understood. Many questions remain to be answered on the molecular events caused by hsp90 overexpression. However, it is becoming more evident that the specific role of hsp90 overexpression in tumour initiation, progression and metastasis, as well as the nature and cause of such overexpression in specific human tumours may be linked to the activation of specific signalling pathways that results in transcriptional regulation.

Novel approaches are required to explore the hsp90, the highly dynamic and rather low-affinity protein complexes of the protein. These approaches may shed light on the details of its association with the cytoskeleton and its possible involvement in protein targeting, in nuclear and mitotic events. The discovery of the hsp90N isoform as a member of the $90 \mathrm{kDa}$ chaperone family, further increases the number of open questions about the possible similarities and dissimilarities in the action of hsp90 $\alpha$ and hsp $90 ß$ isoforms. The elucidation of their role in various signalling events in cell proliferation, cell differentiation and development will be an area of intensive research in the near future.

\section{Acknowledgements}

We are most grateful to Professor David O. Toft (Department of Biochemistry and Molecular Biology, Mayo Clinic, Rochester, Minnesota) for the supply of the mAbs H9010, AC88, and for helpful discussion. This work was supported by the Ministry of Science, Republic of Serbia, Grant 143002B.

\section{References}

1. Maloney A and Workman P: Hsp90 as a new therapeutic target for cancer therapy: the story unfolds. Expert Opin Biol Ther 2: 3-24, 2002.

2. Soti C, Pal C, Papp B and Csermely P: Molecular chaperones as regulatory elements of cellular networks. Curr Opin Cell Biol 17: 210-215, 2005.

3. Whitesell L, Mimnaugh EG, Costa BDe, Myers CE and Neckers LM: Inhibition of heat shock protein hsp90-pp60 ${ }^{\mathrm{Y}-\mathrm{src}}$ heteroprotein complex formation by benzoquinone ansamycins: essential role for stress proteins in oncogenic transformation. Proc Natl Acad Sci USA 91: 8324-8328, 1994.

4. Vilenchik M, Solit D, Basso A, et al: Targeting wide-range oncogenic transformation via PU24FCI, a specific inhibitor of tumor hsp90. Chem Biol 11: 787-797, 2004.

5. Blagosklonny MV: Hsp90-associated oncoproteins: multiple targets of geldanamycin and its analogs. Leukemia 16: 455-462, 2002.

6. Pratt WB and Toft DO: Regulation of signalling protein function and trafficking by the hsp90/hsp70-based chaperone machinery. Exp Biol Med 228: 111-133, 2003.

7. Workman P: Altered states: selectively drugging the hsp90 cancer chaperone. Trends Mol Med 10: 47-51, 2004.

8. Workman P: Combinatorial attack on multistep oncogenesis by inhibiting the hsp90 molecular chaperone. Cancer Lett 206: 149-157, 2004.

9. Pearl LH and Prodromou C: Structure, function, and mechanism of the hsp90 molecular chaperone. Adv Protein Chem 59: $157-185,2002$.

10. Grammatikakis N, Vultur A, Ramana CV, Siganou A, Schweinfest CW, Watson DK and Raptis L: The role of hsp90N, a new member of the hsp90 family, in signal transduction and neoplastic transformation. J Biol Chem 277: 8312-8320, 2002.

11. Karin $\mathrm{M}$ and Hunter T: Transcriptional control by protein phosphorylation: signal transmission from the cell surface to the nucleus. Curr Biol 5: 747-757, 1995.

12. Angel $P$ and Karin $M$ : The role of jun, fos and the AP-1 complex in cell proliferation and transformation. Biochim Biophys Acta 1072: 129-157, 1991.

13. Goetz MP, Toft DO, Ames MM and Erlichman C: The hsp90 chaperone complex as a novel target for cancer therapy. Ann Oncol 14: 1169-1176, 2003.

14. Pandey $\mathrm{P}$, Saleh $\mathrm{A}$, Nakazawa $\mathrm{A}$, et al: Negative regulation of cytochrome c-mediated oligomerization of Apaf-1 and activation of procaspase- 9 by heat-shock protein 90 . EMBO J 19: 4310-4322, 2000.

15. Mason AB, Burkitt M, Magee CJ, O'Connor D and Greenhalf W: The role of hsp90 in regulation of apoptosis in pancreatic cancer. Br J Cancer 85: 54-55, 2001.

16. Munster PN, Basso A, Solit D, Norton L and Rosen N: Modulation of hsp90 function by ansamycins sensitizes breastcancer cells to chemotherapy-induced apoptosis in an Rbdependent and schedule-dependent manner. Clin Cancer Res 7: 2228-2236, 2001

17. Hostein I, Robertson D, Distefano F, Workman P and Clarke PA: Inhibition of signal-transduction by the hsp90 inhibitor 17allylamine-17-demethoxygeldanamycin results in cytostasis and apoptosis. Cancer Res 61: 4003-4009, 2001.

18. Gebhard B, Schutz G, Ecker RC, Steiner GE, Rudas M, Gnant M and Oehler R: MHC-class-I expression in human breast cancer correlates with nuclear localization of the $90 \mathrm{kDa}$ heat-shockprotein. Anticancer Res 19: 5293-5298, 1999.

19. Jolly C and Morimoto RI: Role of the heat shock response and molecular chaperones in oncogenesis and cell death. J Natl Cancer Inst 92: 1564-1572, 2000.

20. Yamada T, Hashiguchi A, Fukushima S, Kakita Y, Umezawa A, Maruyama T and Hata J-I: Function of $90 \mathrm{kDa}$ heat shock protein in cellular differentiation of human embryonal carcinoma cells. In Vitro Cell Dev Biol Anim 36: 139-146, 2000.

21. Helmbrecht K, Zeise E and Rensing L: Chaperones in cell cycle regulation and mitogenic signal transduction. Cell Prolif 33: 341-365, 2000.

22. Morson BC and Sobin LH: Histological typing of intestinal tumors. In: International Histological Classification of Tumor. No. 15, WHO, Geneva, 1976.

23. Blobel G and Potter VR: Nuclei from rat liver: isolation, method that combines purity with high yield. Science 154: 1662-1665, 1966. 
24. Bauer HC and Hurtenbach U: Murine cortical brain cells are autoantigenic from a distinct developmental stage onwards. J Neuroimmunol 12: 1-13, 1986.

25. Lowry OH, Rosenbrough NJ, Farr AL and Ransdall RJ: Protein measurement with the folin phenol reagent. J Biol Chem 193: 265-275, 1951 .

26. Pennial R: An improved method for the determination of inorganic phosphate by the isobutanol-benzene extraction procedure. Anal Biochem 14: 87-90, 1966.

27. Beauge L, Di Polo R, Osses L, Barnola F and Campos M: A $\left(\mathrm{Ca}^{2+}, \mathrm{Mg}^{2+}\right)$-ATPase activity in plasma membrane fragments isolated from squid nerves. Biochim Biophys Acta 644: 147-152, 1981.

28. Laemmli UK: Cleavage of structural proteins during the assembly of the head of bacteriophage T4. Nature 277: 680-685 1970.

29. Towbin H, Staechelin T and Gordon J: Electrophoretic transfer of protein from polyacrylamide gels to nitrocellulose sheets: procedure and some applications. Proc Natl Acad Sci USA 76: 4350-4354, 1979

30. Riehl RM, Sulivan WP, Vroman BT, Bauer VJ, Pearson GR and Toft DO: Immunological evidence that the non-hormone binding component of avian steroid receptors exists in a wide range of tissues and species. Biochemistry 24: 6585-6591, 1985.

31. Midgley R and Kerr D: Colorectal cancer. Lancet 353: 391-399, 1999.

32. Arends WJ: Molecular interactions in the Vogelstein model of colorectal carcinoma. J Pathol 190: 412-416, 2000.

33. Watanabe $\mathrm{T}$ and Muto T: Colorectal carcinogenesis based on molecular biology of early colorectal cancer, with special reference to nonpolypoid (superficial) lesions. World J Surg 24: 1091-1097, 2000.

34. Takayama T, Miyanishi K, Hayashi T, Sato Y and Nirrsu Y: Colorectal cancer: genetics of development and metastasis. J Gastroenterol 41: 185-192, 2006.

35. Calderwood SK, Khaleque MA, Sawyer DB and Ciocca DR: Heat shock proteins in cancer: chaperones of tumorigenesis. Trends Biochem Sci 31: 164-172, 2006.

36. Chiosis G: Targeting chaperones in transformed system - a focus on hsp90 and cancer. Expert Opin Ther Targets 10: 37-50, 2006.

37. Kohda T, Kondo K and Oishi M: Cellular hsp90 (hsp86) mRNA level and in vitro differentiation of mouse embryonal carcinoma (F9) cells. FEBS Lett 290: 107-110, 1991.

38. Maruyama T, Umezawa A, Kusakari S, Kikuchi H, Nozaki M and Hata J: Heat shock induces differentiation of human embryonal carcinoma cells into trophectoderm lineages. Exp Cell Res 224: 123-127, 1996.

39. Csermely P, Kajtar J, Hollosi M, Oikarinen J and Somogyi J: The $90 \mathrm{kDa}$ heat shock protein (hsp90) induces the condensation of the chromatin structure. Biochem Biophys Res Commun 202: 1657-1663, 1994

40. Pal JK, Anand S and Joseph J: Association of hsp90 with the heme-regulated eukaryotic initiation factor $2 \alpha$ kinase-a collaboration for regulating protein synthesis. J Biosci 21: 191-205, 1996

41. Wiech H, Buchner J, Zimmermann R and Jakob U: Hsp90 chaperones protein folding in vitro. Nature 358: 169-170, 1992.

42. Pratt WB: The role of heat shock proteins in regulating the function, folding, and trafficking of the glucocorticoid receptor. J Biol Chem 268: 21455-21458, 1993.

43. Jérôme V, Vourch C, Baulieu EE and Catelli MG: Cell cycle regulation of the chicken hsp90 $\alpha$ expression. Exp Cell Res 205: 44-51, 1993.

44. Galea-Lauri J, Latchman DS and Katz DR: The role of the $90 \mathrm{kDa}$ heat shock protein in cell cycle control and differentiation of the monoblastoid cell line U937. Exp Cell Res 226: 243-254, 1996.

45. Catelli MG, Ramachandran C, Gauthier Y, Legagneux V, Quelard C, Baulieu EE and Shyamala G: Developmental regulation of murine mammary-gland $90 \mathrm{kDa}$ heat-shock proteins. Biochem J 258: 895-901, 1989.

46. Sass JB, Weinberg ES and Krone PH: Specific localization of zebrafish hsp90 $\alpha$ during normal muscle development. Mech Dev 54: 195-204, 1996.

47. Pratt WB: The hsp90-based chaperone system: involvement in signal transduction from a variety of hormone and growth factor receptors. Proc Soc Exptl Biol Med 217: 420-434, 1998.
48. Blagosklonny MV, Toretsky J, Bohen S and Neckers L: Mutant conformation of p53 translated in vitro or in vivo requires functional hsp90. Proc Natl Acad Sci USA 93: 8379-8383, 1996

49. Sepehrnia B, Paz IB, Dasgupta G and Momand J: Heat-shock protein 84 forms a complex with mutant p53 protein predominantly within a cytoplasmic compartment of the cell. J Biol Chem 271: 15084-15090,1996.

50. Teng SC, Chen YY, Su YN, Chou PC, Chiang YC, Tseng SF and Wu KJ: Direct activation of hsp90A transcription by c-Myc contributes to c-Myc-induced transformation. J Biol Chem 279 14649-14655, 2004

51. Lebeau J, Le Chalony C, Prosperi MT and Goubin G: Constitutive overexpression of a $89 \mathrm{kDa}$ heat shock protein gene in the HBL100 human mammary cell line converted to a tumorigenic phenotype by the EJ/T24 Harvey-ras oncogene. Oncogene 6 : $1125-1132,1991$

52. Yufu Y, Nishimura $\mathbf{J}$ and Nawata $\mathrm{H}$ : High constitutive expression of heat shock protein $90 \alpha$ in human acute leukemia cells. Leuk Res 16: 597-605, 1992.

53. Neckers L and Ivy SP: Heat shock protein 90. Curr Opin Oncol 15: 419-424, 2003

54. Gabai VL and Kabakov AE: Induction of heat-shock protein synthesis and thermotolerance in EL-4 ascites tumor cells by transient ATP depletion after ischemic stress. Exp Mol Pathol 60: 88-99, 1994

55. Legagneux V, Mezger V, Quelard C, Barnier JV, Bensaude O and Morange M: High constitutive transcription of hsp86 gene in murine embryonal carcinoma cells. Differentiation 41: 42-48, 1989.

56. Ferrarini M, Heltai S, Zocchi MR and Rugarli C: Unusual expression and localization of heat-shock proteins in human tumor cells. Int J Cancer 51: 613-619, 1992.

57. Gabai VL, Mosina VA, Budagova KR and Kabakov AE: Spontaneous overexpression of heat-shock proteins in Ehrlick ascites carcinoma cells during in vivo growth. Biochem Mol Biol Int 35: 95-102, 1995

58. Chant ID, Rose PE and Morris AG: Analysis of heat-shock protein expression in myeloid leukaemia cells by flow cytometry. Br J Haematol 90: 163-168, 1995.

59. Pia Protti M, Heltai S, Bellone M, Ferrarini M, Manfredi AA and Rugarli C: Constitutive expression of the heat shock protein $72 \mathrm{kDa}$ in human melanoma cells. Cancer Lett 85: 211-216, 1994.

60. Ehrenfried JA, Herron BE, Townsend CM and Evers BM: Heat shock proteins are differentially expressed in human gastrointestinal cancers. Surg Oncol 4: 197-203, 1995.

61. Mileo AM, Fanuele M, Battaglia F, Scambia G, Benedetti-Panici P, Mancuso S and Ferrini U: Selective overexpression of mRNA coding for $90 \mathrm{kDa}$ stress-protein in human ovarian cancer. Anticancer Res 10: 903-906, 1990.

62. Gress TM, Muller-Pillasch F, Weber C, et al: Differential expression of heat shock proteins in pancreatic carcinoma. Cancer Res 54: 547-551, 1994.

63. Nanbu K, Konishi I, Komatsu T, et al: Expression of heat shock proteins hsp70 and hsp90 in endometrial carcinomas. Correlation with clinicopathology, sex steroid receptor status, and p53 protein expression. Cancer 77: 330-338, 1996.

64. Menoret A, Meflah K and Le Pendu J: Expression of the $100 \mathrm{kDa}$ glucose-regulated protein (GRP100/endoplasmin) is associated with tumorigenicity in a model of rat colon adenocarcinoma. Int J Cancer 56: 400-405, 1994.

65. Cai JW, Henderson BW, Shen JW and Subjeck JR: Induction of glucose regulated proteins during growth of a murine tumor. J Cell Physiol 154: 229-237, 1993.

66. Jameel A, Skilton RA, Campbell TA, Chander SK, Coombes RC and Ligmani YA: Clinical and biological significance of hsp89c in human breast cancer. Int J Cancer 50: 409-415, 1992.

67. Franzen B, Linder S, Alaiya AA, et al: Analysis of polypeptide expression in benign and malignant human breast lesions-down regulation of cytokeratins. Br J Cancer 74: 1632-1638, 1996

68. Haverty AA, Harmey JH, Redmond HP and Bouchier-Hayes DJ Interleukin-6 upregulates gp96 expression in breast cancer. J Surg Res 69: 145-149, 1997.

69. Yano M, Naito Z, Tanaka S and Asano G: Expression and roles of heat shock proteins in human breast cancer. Jpn J Cancer Res 87: 908-915, 1996

70. Luparello $\mathrm{C}$ and Noel A: Pucciminafra I. Intratumoral heterogeneity for hsp90ß mRNA levels in a breast cancer cell line. DNA Cell Biol 16: 1231-1236, 1997. 
71. Denis MG, Chadeneau C, Blanchardie P and Lustenberger P: Biological effects of glucocorticoid hormones on two rat colon adenocarcinoma cell lines. J Steroid Biochem Mol Biol 41: 739-745, 1992.

72. Landers JP and Spelsberg TC: New concepts in steroid hormone action: transcription factors, proto-oncogenes, and the cascade model for steroid regulation of gene expression. Crit Rev Eukaryot Gene Expr 2: 19-63, 1992.

73. Bertram J, Palfner K, Hiddemann W and Kneba M: Increase of P-glycoprotein mediated drug resistance by hsp90ß. Anticancer Drugs 7: 838-845, 1996.

74. Jolly C, Michelland S, Rocchi M, Robert-Nicoud M and Vourch C: Analysis of the transcriptional activity of amplified genes in tumour cells by fluorescence in situ hybridization. Hum Genet 101: 81-87, 1997.
75. Kallioniemi A, Kallioniemi OP, Sudar D, Rutovitz D, Gray JW, Waldman FM and Pinkel D: Comparative genomic hybridization for molecular cytogenetic analysis of solid tumors. Science 258 : 818-821, 1992.

76. Basu S, Binder RJ, Ramalingam T and Srivastava PK: CD91 is a common receptor for heat shock proteins gp96, hsp90, hsp70, and calreticulin. Immunity 14: 303-313, 2001.

77. Hanahan D and Weinberg RA: The hallmarks of cancer. Cell 100: 57-70, 2000.

78. Eustace BK, Sakurai T, Steward JK, et al: Functional proteomic screens reveal an extracellular role for hsp90 alpha in cancer cell invasiveness. Nat Cell Biol 6: 507-514, 2004.

79. Picard D: Hsp90 invades the outside. Nat Cell Biol 6: 479-480, 2004. 